\title{
In vivo fragmentation of microporous polyurethane- and copolyesterether elastomer-based vascular prostheses
}

\author{
W.L.J. Hinrichs, J. Kuit, H. Feil, Ch.R.H. Wildevuur* and J. Feijen \\ Department of Chemical Technology, University of Twente, PO BOx 217, 7500 AE Enschede, The \\ Netherlands: "Department of Experimental Cardiopuimonary Surgery, Research Division, University Hospltal \\ of Groningen, PO Box 30.001, 9700 RB Groningen. The Netherlands
}

\begin{abstract}
A previous study showed that microporous, compliant and (bio)degradable vascular prostheses prepared from a polyurethane/poly(L-lactic acid) mixture can function as a temporary scaffold for the regeneration of small-calibre arteries. In this study the mechanism of fragmentation of vascular prostheses made of polyurethane, copolyesterether and blends of either polyurethane or copolyesterether with polymers differing in biodegradability, crystallinity and glass transition temperature is investigated. Animal studies revealed that after 6 wk of implantation only the prostheses made of blends containing a second polymer which was nonelastic at $37^{\circ} \mathrm{C}$ were fragmented extensively, whether the second polymer was (bio)degradable or not. It is concluded that fragmentation of the prostheses is mainly caused by alternating stresses induced by the arterial pulsations and that (bio)degradation plays a minor role.
\end{abstract}

Keywords: Vascular prostheses, polyurethane, degradation

Received 10 January 1991; revised 31 July 1991; accepted 4 September 1991

No suitable material for the reconstruction of arteries of small diameter is available. A high incidence of graft failure can often be ascribed to a lack of compliance and/ or the poor healing characteristics of the materials used ${ }^{1-5}$. However, recent studies have shown that grafts which are elastic, microporous and biodegradable are promising ${ }^{6-12}$. Prostheses with these characteristics were prepared from a polyurethane/poly(L-lactic acid) mixture ${ }^{13,14}$. When replacing a $1 \mathrm{~cm}$ segment of the abdominal aorta of a rat by such a prosthesis the graft acts as a temporary scaffold for the regeneration of the arterial wall. Simultaneously with the regeneration of the arterial wall, the prosthesis fragments. In the ideal case the rate of tissue regeneration and the rate of disintegration of the prosthesis correspond such that the mechanical properties of the graft together with the ingrown tissue remain the same in time. Remarkable in the study mentioned was the very high rate of regeneration of the arterial wall. Within $6 \mathrm{wk}$ almost complete healing of the graft was observed. Even more remarkable was the very high rate of fragmentation of the prosthetic material which appeared to be dependent on the polyurethane/ poly(L-lactic acid) ratio and the molecular weight of poly(L-lactic acid). Implantation of prostheses of polyurethane/poly(L-lactic acid) $(80 / 20 \mathrm{w} / \mathrm{w})$ using a poly(Llactic acid) with viscosity-average mol wt 100000 resulted in aneurysms after $6 \mathrm{wk}$ indicating extensive

Correspondence to Professor /. Feijen. fragmentation of the prosthetic material. In contrast no aneurysms were observed when using prostheses prepared from polyurethane/poly[L-lactic acid] $(95 / 5 \mathrm{w} / \mathrm{w})$ using poly(L-lactic acid) with viscosity-average mol wt 500000 indicating reduced fragmentation. However, pinocytosis of fragments of the prosthetic material by multinucleated giant cells after $6 \mathrm{wk}$ of implantation was observed indicating fragmentation of the graft. Finally, grafts prepared from pure polyurethane showed no fragmentation after $6 \mathrm{wk}$ of implantation.

Two mechanisms have been proposed to explain the unexpected behaviour of the blend materials. In the first mechanism, (bio)degradation of poly(L-lactic acid) is supposed to cause fragmentation of the prosthesis ${ }^{14}$. However, the degradation rate of poly(L-lactic acid) is rather low ${ }^{15,16}$. Because the degradation of this (semi)crystalline polymer predominantly proceeds via the amorphous phase ${ }^{15-17}$ a high rate of degradation can only be expected when poly(L-lactic acid) in the blend has a decreased crystallinity which may be caused by an even distribution of the poly(L-lactic acid) chains over the polyurethane matrix. In the second mechanism, exposure of the graft to alternating mechanical stresses caused by the arterial pulsations is supposed to cause fragmentation of the prosthesis ${ }^{18}$. In this case it is assumed that poly( $\mathrm{L}^{-}$ lactic acid) forms rigid domains in an elastic matrix of polyurethane. Stress concentrations around these rigid domains, caused by the stresses exerted on the prostheses, will result in small ruptures which will propagate 
through the polyurethane matrix leading to fragmentation of the graft.

In this study we investigated whether the high rate of fragmentation is restricted to the combination polyurethane/poly(L-lactic acid) and which mechanism underlies this behaviour. Microporous and elastic vascular prostheses were made of polyurethane, copolyesterether and blends of either polyurethane or copolyesterether with polymers differing in biodegradability, crystallinity and glass transition temperature. The prostheses were used to replace a $1 \mathrm{~cm}$ segment of the abdominal aorta in rats. At 6 wk after implantation the degree of fragmentation of the grafts was studied.

The various blends were investigated by differential scanning calorimetry, scanning electron microscopy and dynamic mechanical measurements. The degree of fragmentation could be related with the physical/chemical properties of the polymers and the distribution of the polymers in the blends.

On the basis of the results a model is proposed for a clinically applicable (bio)degradable vascular prosthesis.

\section{MATERIALS AND METHODS}

\section{Materials}

Polymers were used after being purified by precipitation from solutions into non-solvents (see Table 1) ${ }^{19.20}$. Sodium citrate (Janssen Chimica, Tilburg, The Netherlands) was recrystallized from a water/methanol mixture. Fractions with different particle sizes were obtained using Tamson test sieves (Zoetermeer, The Netherlands). Synthesis grade $N, N$-dimethylformamide (DMF), tetrahydrofuran (THF), chloroform $\left(\mathrm{CHCl}_{3}\right)$, 1,4-dioxane and chemical grade methanol and ethanol (all Merck, Darmstadt, Germanyl were used without further purification.

\section{Graft preparation}

Microporous elastic vascular prostheses with the following compositions (see Table 1 for abbreviations) were prepared: PEU and blends of PEU and PESU, PCL, PGLY, PLLA (MM), PLLA (HM), or PSF (9/1 w/w), and Hytrel and blends of Hytrel and PLLA (LM), PLLA (HM), PSF or PEU $(9 / 1 \mathrm{w} / \mathrm{w})$.

The PEU-based prostheses were prepared by a modified dipcoating procedure developed by Gogolewski et $a l^{13,14}$. A glass rod with the desired diameter was dipped into a suspension of a polymer solution and sodium citrate particles (for compositions see Table 2). The temperature of the casting suspensions was adjusted such that the casting procedure resulted in the deposition of thin and regular layers on to the glass rod. For the various compositions, the temperature had to be adjusted to different levels between 40 and $60^{\circ} \mathrm{C}$. Subsequently, the glass rod on which a layer of the suspension was deposited was transferred into ethanol/water at 12/0, 11/ 1 or $10 / 2(\mathrm{v} / \mathrm{v})$ for $10 \mathrm{~s}$ at room temperature. Thereafter, the glass rod was transferred into ethanol/water at $7 / 5[\mathrm{v} /$ v) also at room temperature. After 5-10 min the precipilated polymer was dried by air exposure and the subsequent layer was deposited by the same procedure. After the desired number of layers was prepared the prostheses were placed in ethanol/water at $7 / 5(\mathrm{v} / \mathrm{v})$ for at least $30 \mathrm{~min}$. Subsequently, they were placed in a water bath at $40-50^{\circ} \mathrm{C}$ for $2 \mathrm{~h}$ to dissolve the salt particles. The prostheses were then thoroughly rinsed with distilled water and ethanol, removed from the glass rods and stored in ethanol.

The Hytrel-based prostheses were prepared in a similar way. Also these prostheses were prepared by depositing a number of porous layers on to a glass rod by dipcoating. However, the method of polymer precipitation was changed: after the glass rod was dipped into a polymer solution/salt particles suspension (for composition see Table 2), the glass rod containing the layers was exposed to air allowing the solvent to evaporate. After 1-3 min the next layer was formed by the same procedure. Dipcoating was performed at room temperature, and repeated until the required wall thickness was obtained. Subsequently the prostheses were exposed to air for at least $30 \mathrm{~min}$. Thereafter, they were treated like the PEU-based prostheses.

\section{Characterization of the grafts}

The prostheses were evaluated for porosity, ruptures, pinholes, regularity of the wall thickness and linkage of

Table 1 Polymers used for the preparation of the grafts and solvent/non-solvent combinations for polymer purification

\begin{tabular}{|c|c|c|c|c|}
\hline Polymer & Manufacturer & Abbreviation & Solvent & Non-solvent \\
\hline Polyetherurethane, Estane ${ }^{\circledR} 5714 \mathrm{f} 1$ & $\begin{array}{l}\text { Goodrich, Leidschendam, } \\
\text { The Netherlands }\end{array}$ & PEU & DMF & Water \\
\hline Polyesterurethane, Estane ${ }^{\infty} 5707 f 1$ & $\begin{array}{l}\text { Goodrich, Leidschendam, } \\
\text { The Netherlands }\end{array}$ & PESU & DMF & Water \\
\hline Copolyesterether, Hytrel ${ }^{\star} 4056$ & $\begin{array}{l}\text { Du Pont de Nemour, Mechelen, } \\
\text { Belgium }\end{array}$ & Hytrel & $\mathrm{CHCl}_{3}$ & Ethanol \\
\hline Poly- $\varepsilon$-caprolactone $\left(M_{\mathrm{v}}: 70000\right)^{\mathrm{a}}$ & $\begin{array}{l}\text { Oce van der Grinten, Venlo, } \\
\text { The Netherlands }\end{array}$ & $\mathrm{PCL}$ & THF & Methanol \\
\hline $\begin{array}{l}\text { Polyglycine (Mol wt: } 2000) \\
\text { Poly(L-lactic acid) }\left(M_{\mathrm{v}}: 50000\right)^{\mathrm{a}} \\
\text { Poly(L-lactic acid) }\left(M_{\mathrm{v}}: 100000\right)^{\mathrm{a}} \\
\text { Poly(L-lactic acid) }\left(M_{\mathrm{v}}: 380000\right)^{\mathrm{a}} \\
\text { Polysulfone P3500 }\end{array}$ & $\begin{array}{l}\text { Sigma, St Louis, USA } \\
\text { CCA, Gorinchem, The Netherlands } \\
\text { CCA, Gorinchem, The Netherlands } \\
\text { CCA, Gorinchem, The Netherlands } \\
\text { Union Carbide, Antwerp, Belgium }\end{array}$ & $\begin{array}{l}\text { PGLY } \\
\text { PLLA(LM) } \\
\text { PLLA(MM) } \\
\text { PLLA(HM) } \\
\text { PSF }\end{array}$ & $\begin{array}{l}-\mathrm{c} \\
\mathrm{CHCl}_{3} \\
\mathrm{CHCl}_{3} \\
\mathrm{CHCl}_{3} \\
\mathrm{DMF}^{3}\end{array}$ & $\begin{array}{l}-^{c} \\
\text { Methanol } \\
\text { Methanol } \\
\text { Methanol } \\
\text { Water }\end{array}$ \\
\hline
\end{tabular}

${ }^{a}$ The intrinsic viscosity of solutions of PLLA in $\mathrm{CHCl}_{3}$ and of $\mathrm{PCL}$ in THF was determined at $25^{\circ} \mathrm{C}$ with an Ubbelohde viscometer. Viscosity-average mol wt were

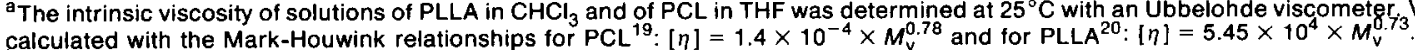
Galculated with the Mark-Houwink relationships for

Not purified. DMF, N,N-dimethyl formamide; THF, tetrahydrofuran; $\mathrm{CHCl}_{3}$, chloroform. 
Table 2 Composition of casting suspensions

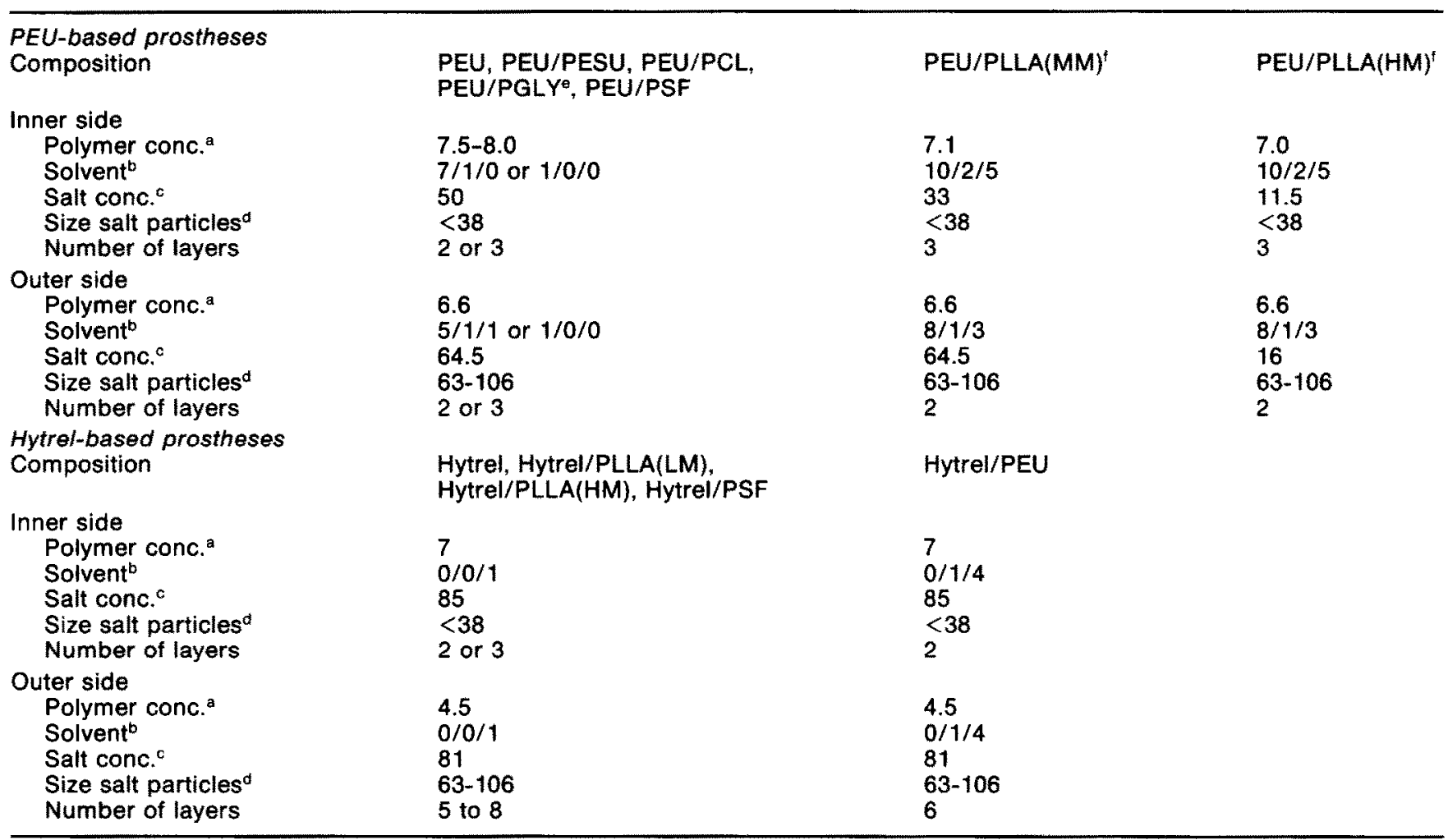

${ }^{a}$ Polymer concentration $(\mathrm{g} / 100 \mathrm{ml})$.

${ }^{\mathrm{B}} \mathrm{Ratio} \mathrm{DMF} / \mathrm{THF} / \mathrm{CHCl}_{3}(\mathrm{v} / \mathrm{v} / \mathrm{v})$.

${ }^{c}$ Concentration of sodium citrate $(g / 100 \mathrm{ml})$

${ }^{\mathrm{d}}$ Particle size $(\mu \mathrm{m})$.

${ }^{2} \mathrm{PGLY}$ does not dissolve in DMF/THF mixtures. PGLY with a particle size $<5 \mu \mathrm{m}$ was suspended in the PEU solutions.

since DMF/THF mixtures are poor solvents and $\mathrm{CHCl}_{3}$ is a good solvent for $\mathrm{PLLA}$, before the casting procedure, a solution of PLLA in $\mathrm{CHCl}$, was added dropwise under vigorous stirring to a solution of PEU in a mixture of DMF and THF until a solution with the desired composition was obtained.

For abbreviations of polymers see Table 1.

the subsequent layers with a Zeiss stereo light microscope. The wall thickness was determined by light microscopy.

After being coated with a layer of gold by a Balzer sputter unit, the pore structure of the prostheses was examined with a Jeol JSM 35 scanning electron microscope (SEM) operating at $15 \mathrm{kV}$.

The longitudinal elasticity of the prostheses was determined as follows. Shortly before the measurements, the prostheses were rinsed with distilled water and subsequently fixed between the clamps of a Instron tensile tester (Floor model TT-CM). The prostheses of length $1 \mathrm{~cm}$ were drawn at $0.5 \mathrm{~cm} / \mathrm{min}$ to $2 \mathrm{~cm}$. The measured stress at this strain gave the $F_{100 \%}$ value.

In a number of cases stress-strain measurements in the radial direction were also performed. Prostheses of length $0.5 \mathrm{~cm}$ were drawn at $0.5 \mathrm{~cm} / \mathrm{min}$ with the setup shown in Figure 1. The measured stress and elongation at failure gave the $\mathrm{SF}$ and the $\mathrm{EF}$ values respectively.

\section{Compatibility of the blends}

A number of techniques were applied to evaluate the compatibility of the blends. Both dense membranes and porous prostheses were investigated. The dense membranes were prepared by solution casting techniques.

The crystallinity of PCL and PLLA in the prostheses made of PEU/PCL, PEU/PLLA (MM), PEU/PLLA (HM), Hytrel/PLLA (LM) and Hytrel/PLLA (HM) (9/1 w/w) and

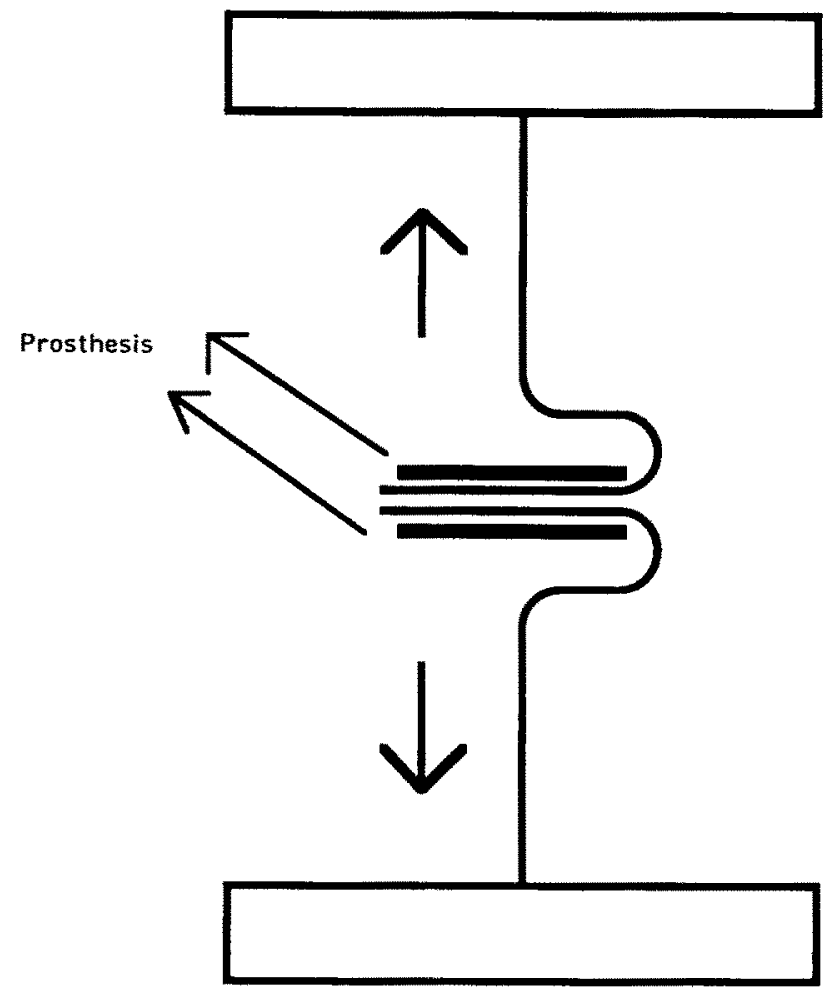

Figure 1 Set-up for stress-strain measurements of the grafts in the radial direction. 
in the dense membranes made of Hytrel/PLLA (LM) and Hytrel/PLLA (HM) (9/1 w/w) and of starting materials PCL and PLLA were determined by differential scanning calorimetry (Du Pont 990 thermal analyser) using a heating rate of $10^{\circ} \mathrm{C} / \mathrm{min}$.

Glass transition temperatures of prostheses and dense membranes made of Hytrel and blends of Hytrel and PLLA (LM), PLLA (HM), PSF and PEU (9/1 w/w) were determined with a Myrenne ATM 3 torsion pendulum instrument operating at $1 \mathrm{~Hz}$ and a heating rate of $1^{\circ} \mathrm{C} / \mathrm{min}$. The maximum of the $G^{\prime \prime}$ curve was taken as $T_{8}$.

The presence of the second polymer in a number of blends was visualized as follows. Dense membranes made of Hytrel and blends of Hytrel and PLLA (LM), PLLA (HM), PSF and PEU (9/1 w/w) were cut at $-140^{\circ} \mathrm{C}$ with an LKB 2188 Nova cryo-ultratome to obtain crosssections of the materials. The specimens were placed in 1,4-dioxane at room temperature for $15-30 \mathrm{~min}$ to remove the second polymers in the blends. After drying, the 1,4-dioxane-treated and untreated samples were sputter-coated with gold and examined with SEM.

\section{Implantation}

Prostheses of length $1 \mathrm{~cm}$ were used to replace a $1 \mathrm{~cm}$ segment of the abdominal aorta of adult male Wistar rats $(n=3)$. The implantation was performed according to a standardized procedure ${ }^{6}$. The grafts were harvested $6 \mathrm{wk}$ after implantation and stored in ethanol.

\section{Trypsin/collagenase treatment}

The explanted grafts were thoroughly rinsed with distilled water and subsequently incubated with $10 \%$ trypsin/EDTA [Gibco Europe, Breda, The Netherlands] at $37^{\circ} \mathrm{C}$ for $24 \mathrm{~h}$. Then the trypsin/EDTA solution was replaced by a $0.3 \%$ solution of collagenase (type 1 , Sigma, St Louis, USA) in phosphate-buffered saline (NPBI, Emmer-Compascuum, The Netherlands). After 2-4 d, the grafts were thoroughly rinsed with distilled water, examined macroscopically, and in some cases subjected to mechanical tests. Unimplanted prostheses served as controls.

\section{RESULTS}

\section{Graft preparation}

Figure 2 shows SEM photographs of the PEU and the Hytrel prostheses. The morphology of the grafts can be described as a highly interconnected sponge-like structure. The pore diameter on the inner side of the prostheses was $30 \mu \mathrm{m}$ and on the outer side $75 \mu \mathrm{m}$. The prostheses made of the blends had a similar appearance. Wall density varied with the composition of the graft material from 0.11 to $0.30 \mathrm{mg} / \mathrm{mm}^{3}$ giving a volume porosity of about 90-70\% (Table 3). The $F_{100 \%}$ and the wall thickness varied with the composition of the graft material and were 0.40-1.95 $\mathrm{N}$ and $0.30-0.60 \mathrm{~mm}$ respectively (Table 3 ).

It was attempted to prepare the various types of prostheses with the same characteristics such as wall thickness, elasticity and porosity. However, due to variation of the mechanical properties of the polymers, phase separation, and/or the viscosity of the casting
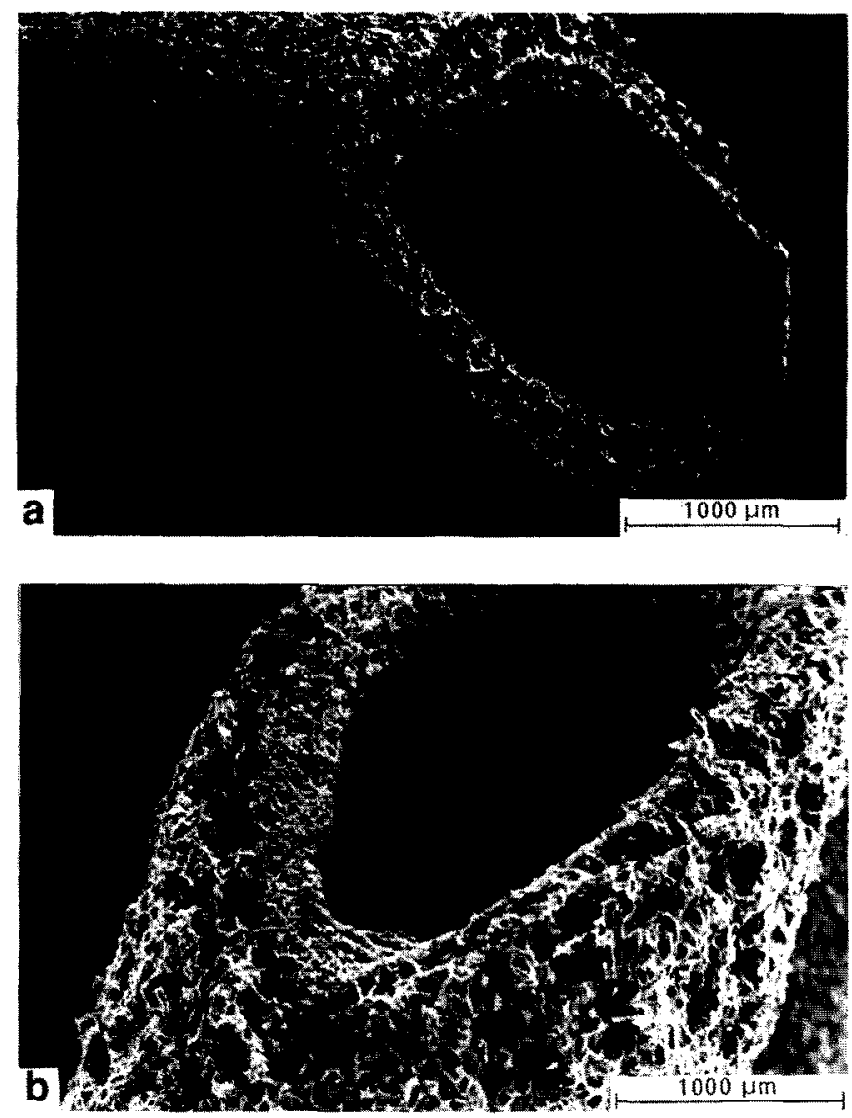

Figure 2 Scanning electron micrographs of a the PEU and $\mathbf{b}$ the Hytrel prostheses.

suspensions this was not always possible (Table 3). To prepare the PEU/PLLA(MM) and the PEU/PLI.A(HM) prostheses with sufficient strength, it was necessary to reduce the sodium citrate concentration in the casting suspensions thereby reducing the porosity of the resultant prostheses as compared with the other PEU-based prostheses. Hytrel has a higher $E$ modulus than $\mathrm{PEU}^{23}$. The Hytrel-based prostheses exhibited higher $F_{100 \%}$ than the PEU-based prostheses.

\section{Compatibility}

From differential scanning calorimetry, it appeared that the crystallinity of PCL in the prosthesis was reduced to $75 \%$ as compared to the starting material (Table 4$)^{21,22}$. Thus a large fraction of PCL had formed crystalline domains. A reduction of the crystallinity of PCL in the blend compared to the starting material might indicate some mixing of the PCL chains over the PEU matrix, but it is also possible that domains with reduced crystallinity were formed. The differential scanning calorimetry thermograms of the PEU/PLLA(MM) and the PEU/ PLLA(HM) prostheses showed two peaks between 160 and $180^{\circ} \mathrm{C}$. The melting enthalpies of the two peaks together and of the starting materials were nearly equal, indicating a strong inhomogeneous distribution of the polymers in the blend. Leenslag et al., who also studied the melting behaviour of PEU/PLLA blends, found two peaks in the thermograms ${ }^{18}$. It was suggested that two types of crystal lattices were formed, one type was supposed to consist of pure PLLA while in the other PEU 
Table 3 Characteristics of the prostheses

\begin{tabular}{|c|c|c|c|c|c|}
\hline Composition & $\begin{array}{l}\text { Wall } \\
\text { thickness } \\
(\mathrm{mm})\end{array}$ & $\begin{array}{l}\text { Internal } \\
\text { diameter } \\
(\mathrm{mm})\end{array}$ & $\begin{array}{l}\text { Pore } \\
\text { diameter } \\
(\mu \mathrm{m})\end{array}$ & $\begin{array}{l}\text { Wall } \\
\text { density } \\
\left(\mathrm{mg} / \mathrm{mm}^{3}\right)\end{array}$ & $\begin{array}{l}F_{100 \%} \\
(\mathrm{~N})^{\mathrm{b}}\end{array}$ \\
\hline PEU & 0.60 & 1.3 & $30-75$ & 0.31 & 0.95 \\
\hline PEU/PESU $(9 / 1)$ & 0.60 & 1.3 & $30-75$ & 0.11 & 0.95 \\
\hline PEU/PCL $(9 / 1)$ & 0.30 & 1.3 & $30-75$ & 0.17 & 0.90 \\
\hline PEU/PGLY (9/1) & 0.30 & 1.3 & $30-75$ & 0.11 & 0.40 \\
\hline PEU/PLLA(MM) $(9 / 1)$ & 0.45 & 1.5 & $30-75$ & 0.25 & 0.60 \\
\hline PEU/PLLA(HM) $(9 / 1)$ & 0.35 & 1.3 & $30-75$ & 0.30 & 0.50 \\
\hline PEU/PSF $(9 / 1)$ & 0.30 & 1.3 & $30-75$ & 0.16 & 0.70 \\
\hline Hytrel & 0.50 & 1.5 & $30-75$ & 0.18 & 1.05 \\
\hline Hytrel/PLLA(LM) $(9 / 1)$ & 0.50 & 1.5 & $30-75$ & 0.18 & 1.25 \\
\hline Hytrel/PLLA(HM) $(9 / 1)$ & 0.55 & 1.5 & $30-75$ & 0.17 & 1.35 \\
\hline Hytrel/PSF $(9 / 1)$ & 0.50 & 1.5 & $30-75$ & 0.16 & 1.80 \\
\hline Hytrel/PEU (9/1) & 0.50 & 1.5 & $30-75$ & 0.27 & 1.95 \\
\hline
\end{tabular}

${ }^{\text {a }}$ Pore diameter inner side - outer side.

${ }^{b}$ Values are mean of three measurements; error of the mean is maximally $10 \%$

For abbreviations of polymers see Table 1 .

Table 4 Differential scanning calorimetry measurements on polymers, dense membranes and vascular prostheses

\begin{tabular}{|c|c|c|}
\hline & $T_{m}\left({ }^{\circ} \mathrm{C}\right)$ & $\Delta H_{1}(\mathrm{~J} / \mathrm{g})$ \\
\hline $\begin{array}{l}\text { PCL ( } 100 \% \text { crystalline })^{21} \\
\text { PCL (starting material) } \\
\text { PEU/PCL prosthesis }\end{array}$ & $\begin{array}{l}- \\
63 \\
63\end{array}$ & $\begin{array}{r}139.5 \\
84.4 \\
64.3\end{array}$ \\
\hline $\begin{array}{l}\text { PLLA }\left(100 \%{\text { crystalline })^{22}}\right. \\
\text { PLLA(MM) (starting material) } \\
\text { PEU/PLLA(MM) prosthesis }\end{array}$ & $\begin{array}{r}- \\
172 \\
167 / 174\end{array}$ & $\begin{array}{c}93.7 \\
33 \\
15 / 16\end{array}$ \\
\hline $\begin{array}{l}\text { PLLA (100\% crystalline })^{22} \\
\text { PLLA(HM) (starting material) } \\
\text { PEU/PLLA(HM) prosthesis } \\
\text { Hytrel/PLLA(HM) prosthesis } \\
\text { Hytrel/PLLA(HM) dense membrane }\end{array}$ & $\begin{array}{r}- \\
172 \\
167 / 176 \\
172 \\
172\end{array}$ & $\begin{array}{c}93.7 \\
32 \\
18 / 17 \\
18 \\
18\end{array}$ \\
\hline $\begin{array}{l}\text { PLLA (100\% crystalline) })^{22} \\
\text { PLLA(LM) (starting material) } \\
\text { Hytrel/PLLA(LM) prosthesis } \\
\text { Hytrel/PLLA(LM) dense membrane }\end{array}$ & $\begin{array}{l}- \\
172 \\
172 \\
172\end{array}$ & $\begin{array}{l}93.7 \\
54 \\
31 \\
31\end{array}$ \\
\hline
\end{tabular}

For abbreviations of polymers see Table 1.

chains are entrapped in the PLLA matrix. However, others have found that under certain conditions pure PLLA can also yield two melting peaks in the thermograms $(H$. Esselbrugge and J. Feijen, personal communication). This may be caused by the formation of two types of crystal lattices differing in size or structure or both. In the Hytrel/PLLA(LM) and the Hytrel/PLLA(HM) prostheses, PLLA was also partially crystalline indicating an inhomogeneous distribution of the polymers in the blend. In contrast to the PEU/PLLA prostheses, the thermograms of both types of prostheses showed single melting peaks at $172^{\circ} \mathrm{C}$. A crystallinity of PLLA(LM) and PLLA(HM) in the blends of respectively $60 \%$ and $50 \%$ compared to the starting materials was found. As with the PEU/PCL prostheses, the reduction of the crystallinity of PLLA in the blends compared to the starting materials might be caused by some mixing of PLLA chains over the Hytrel matrix or by the furmation of domains with a reduced crystallinity. The dense membranes with compositions Hytrel/PLLA(LM) and Hytrel/PLLA(HM) showed identical melting behaviour indicating comparable distributions of the polymers in both blends.

A blend in which the two polymers are mixed on a molecular scale (homogeneous blend) has one $T_{\mathrm{g}}$. This $T_{\mathrm{g}}$ is between the two $T_{g}$ of the pure components. Therefore, if a blend shows two $T_{g}$ which are not changed compared to the $T_{y}$ of the pure components, the polymers in the blend are not mixed or mixed to a limited extent on a molecular scale (inhomogeneous blend). Dynamic torsion measurements were performed to determine the $T_{\mathrm{g}}$ of the materials incorporated in prostheses and dense membranes made of Hytrel and blends of Hytrel and PLLA(LM), PLLA(HM), PSF or PEU. The $G^{\prime \prime}$ curve of the Hytrel prosthesis showed a maximum at $-60^{\circ} \mathrm{C}$ indicating the $T_{\mathrm{g}}$, and a strong decrease at $160^{\circ} \mathrm{C}$ indicating the $T_{\mathrm{m}}$. In the $G^{\prime \prime}$ curves of the prostheses made of blends of Hytrel and PLLA(LM), PLLA(HM), PSF or PEU, neither a shift in the $T_{\mathrm{g}}$ nor in the $T_{\mathrm{m}}$ was observed. Furthermore, the $T_{g}$ of PLLA(LM) and PLLA(HM) could not be detected in the $G^{\prime \prime}$ curve. Presumably this is because PLLA in both the glassy and the rubbery phase possesses a much higher $E$ modulus than Hytrel. As a consequence the energy is transferred to the Hytrel matrix and not to the hard PLLA domains independently whether PLLA is in the glassy or the rubbery phase. The glass transition of PSF could not be detected in the $G^{\prime \prime}$ curve because the $T_{\mathrm{g}}$ of PSF $\left(180^{\circ} \mathrm{C}\right)$ is higher than the $T_{\mathrm{m}}$ of Hytrel. Also in the $G^{\prime \prime}$ curve of the $\mathrm{Hytrel} / \mathrm{PEU}$ prosthesis, only one maximum at $-60^{\circ} \mathrm{C}$ was observed. Since there is only a small difference in the $T_{\mathrm{g}}$ of Hytrel and PEU $\left[T_{\mathrm{g}}(\mathrm{PEU})-40^{\circ} \mathrm{C}\right]$ it remains unclear whether the maximum is the result of one or two glass transitions. The differences between the $T_{g}$ of the pure components in the blend made of Hytrel and PLLA(LM), PLLA(HM) or PSF are large enough to expect a shift in the $T_{\mathrm{g}}$ when homogeneous blends were formed. Therefore, the observed absence of a shift indicates that the polymers were inhomogeneously distributed over the blends. In contrast, the difference between the $T_{\mathrm{g}}$ of Hytrel and PEU is too small and no conclusion can be drawn about the distribution of these polymers in this blend. Furthermore, the dynamic torsion measurements on the porous prostheses and the dense membranes yielded the same results indicating that the distribution of the polymers in both types of blends were comparable.

PLLA(LM), PLLA(HM), PSF and PEU are soluble in 1,4-dioxane, whereas Hytrel is not. Therefore, if these polymers should form domains in the blends they should 
be extractable. In these experiments, dense membranes were used instead of porous structures because with the use of porous structures the pores initially present and the pores which possibly arise as a result of the extraction procedure cannot be distinguished. The untreated Hytrel samples and those treated with 1,4dioxane had non-porous surfaces. The other samples showed porous surfaces indicating that pores had been formed by dissolution of PLLA(LM), PLLA(HM), PSF and PEU from the blends and that indeed these polymers had formed domains. The pore size differed with composition and varied between 1 and $10 \mu \mathrm{m}$ (Figures 3a and $b$ show a scanning electron micrograph of untreated and 1,4-dioxane-treated Hytrel/PLLA(HM) membrane respectively]. Because the dense membranes and the porous prostheses were prepared in a comparable way it can be assumed that in the prostheses PLLA(LM), PLLA(HM), PSF and PEU have also formed domains in the Hytrel matrices. However, the sizes of the domains in the dense membranes and in the prostheses do not have to be necessarily the same.

\section{Implantation and trypsin/collagenase treatment}

The 12 different types of prostheses (length $1 \mathrm{~cm}$ ) were implanted in the abdominal aorta of rats $(n=3)$ and evaluated after 6 wk of implantation. At graft harvesting, all the implants were patent. The PEU/PLLA(MM) and one of the Hytrel/PLLA(LM) prostheses showed aneurysms, whereas the other prostheses were not dilated. Furthermore, all the prostheses showed an extensive perigraft tissue ingrowth. This ingrown tissue was removed by trypsin/collagenase treatment to leave bare prosthetic material. After this, a degree of fragmentation was assessed by visual examination or by tensile measurements (Table 5). The PEU/PLLA(MM], PEU/PCL, and PEU/PSF prostheses showed large ruptures and had lost their mechanical strength completely (Figure $4 a$ is a light micrograph of an explanted and trypsin/collagenasetreated PEU/PSF prosthesis). The PEU/PLLA(HM) and
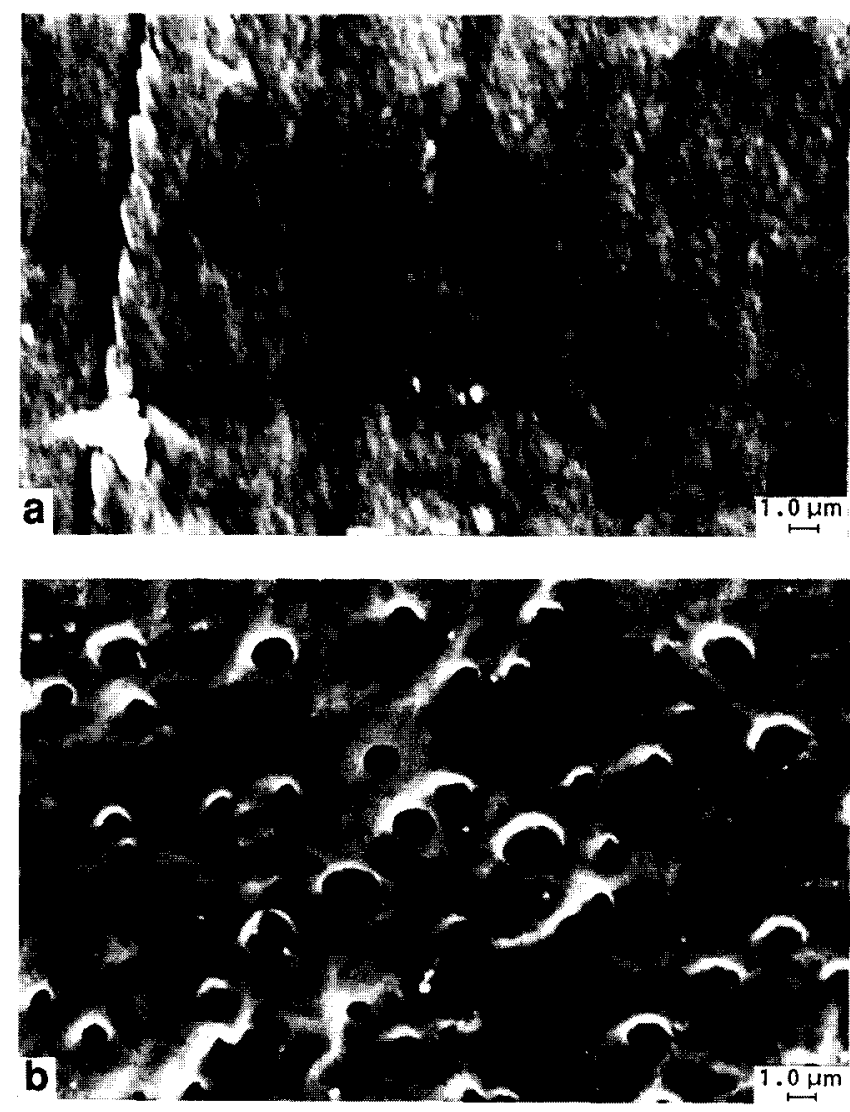

Figure 3 Scanning electron micrographs of dense membranes. a Untreated and b 1,4-Dioxane-treated Hytrel/PLLA(HM) membranes.

PEU/PGLY prostheses showed no visual signs of fragmentation. However, these prostheses lost their mechanical strength completely. A slight decrease of mechanical strength of the PEU and the PEU/PESU prostheses could be determined by stress-strain measurements.

Table 5 Fragmentation of the prostheses after 6 wk of implantation in the rat abdominal aorta

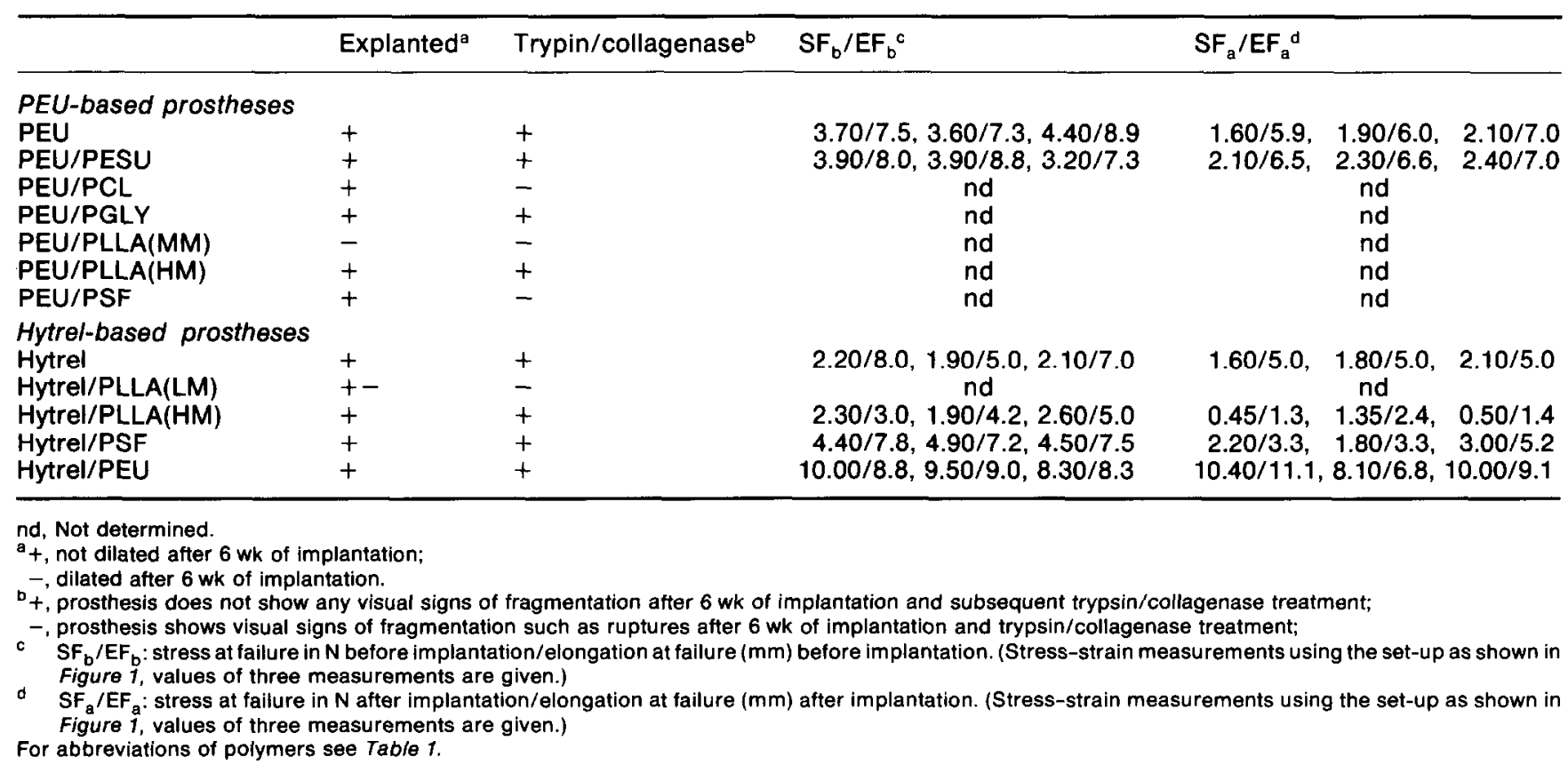



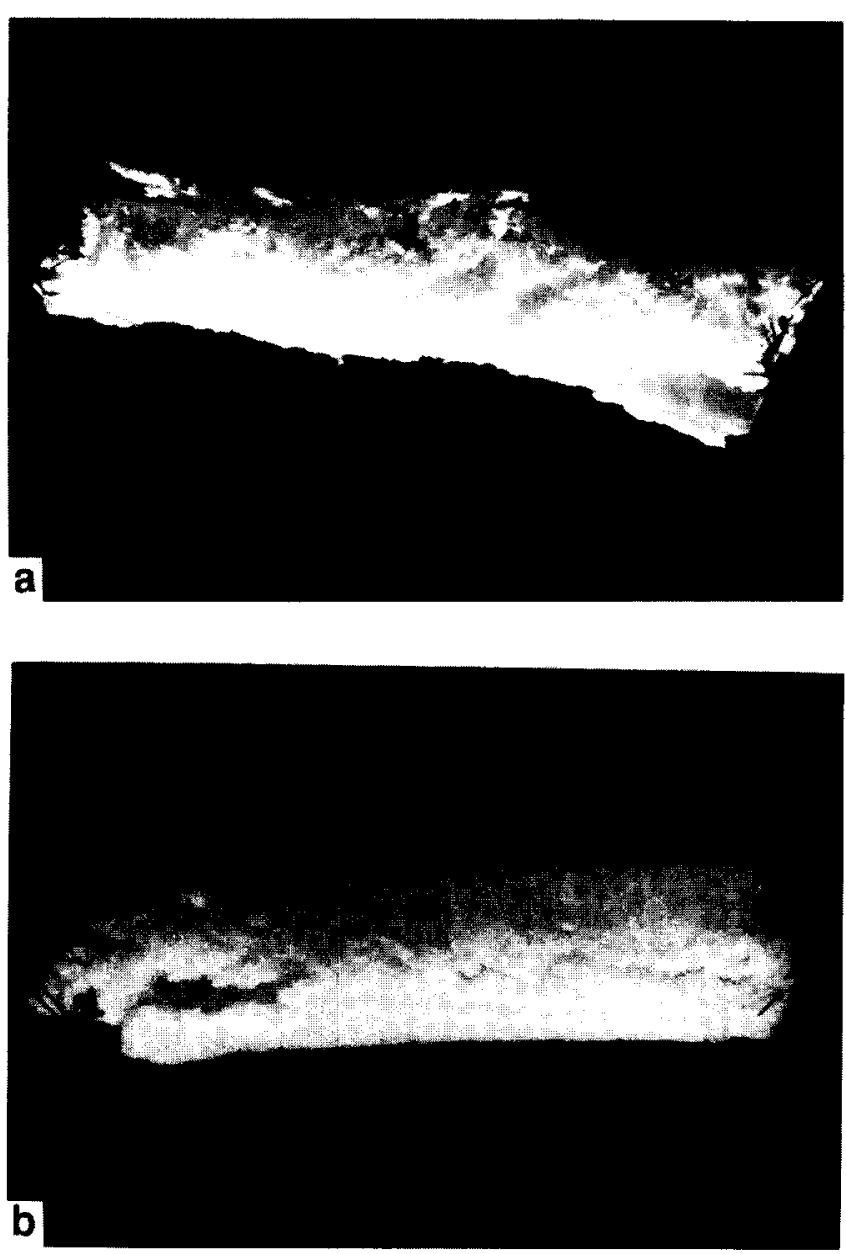

Figure 4 Light micrographs of explanted and subsequently trypsin/collagenese treated prostheses: a PEU/PSF, b Hytrel/ PLLA(LM).

The Hytrel/PLLA(LM) prosthesis which had developed into an aneurysm broke into three picces, the other two showed large ruptures and crumbled when touched (Figure $4 b$ is a light micrograph of an explanted and trypsin/collagenase-treated Hytrel/PLLA(LM) prosthesis). Superficial examinations of the Hytrel/PLLA(HM) and Hytrel/PSF prostheses showed that they were unimpaired. However, fragmentation could be determined by stressstrain measurements. Fragmentation of the Hytrel and the Hytrel/PEU prostheses could not be detected. The mechanical properties before and after implantation were nearly equal.

The trypsin/collagenase treatment did not affect the mechanical properties of the unimplanted prostheses (data not shown).

\section{DISCUSSION}

In vivo experiments with the prostheses made of the nondegradable combinations PEU/PSF and Hytrel/PSF clearly demonstrate that fragmentation after $6 \mathrm{wk}$ of implantation is not restricted to prostheses made of the combination PEU/PLLA and that fragmentation of the prostheses does not necessarily proceed via (bio)degradation. Furthermore, fragmentation of the different
Table 6 Physical/chemical properties of the applied polymers

\begin{tabular}{lccllll}
\hline & $T_{m}\left({ }^{\circ} \mathrm{C}\right)$ & $T_{g}$ & $\begin{array}{l}\mathrm{n} . \mathrm{dg} / \\
\text { el }\end{array}$ & $\begin{array}{l}\mathrm{dg} / \\
\mathrm{el}\end{array}$ & $\begin{array}{l}\mathrm{dg} / \\
\text { n.el }\end{array}$ & $\begin{array}{l}\mathrm{n} . \mathrm{dg} / \\
\mathrm{n} . \mathrm{el}\end{array}$ \\
\hline PEU & - & $<37^{\circ} \mathrm{C}$ & $\times$ & & & \\
PESU & - & $<37^{\circ} \mathrm{C}$ & $\times$ & & & \\
Hytrel & - & $<37^{\circ} \mathrm{C}$ & $\times$ & & & \\
PCL & 60 & $<37^{\circ} \mathrm{C}$ & & & $\times$ & \\
PLLA(LM) & 172 & $>37^{\circ} \mathrm{C}$ & & $\times$ & \\
PLLA(MM) & 172 & $>37^{\circ} \mathrm{C}$ & & $\times$ & \\
PLLA(HM) & 172 & $>37^{\circ} \mathrm{C}$ & & $\times$ & \\
PGLY & - & $>37^{\circ} \mathrm{C}$ & & $\times$ & $\times$ \\
PSF & - & $>37^{\circ} \mathrm{C}$ & & & & $\times$ \\
\hline
\end{tabular}

dg, degradable; n.dg, not or very slowly degradable; el, elastomeric properties at $37^{\circ} \mathrm{C} ; n$.el, not elastic at $37^{\circ} \mathrm{C}$. For abbreviations of polymers see Table 1.

prostheses is related to the physical/chemical properties of the polymers (Tables 5 and 6 ). Only prostheses made of blends of either PEU or Hytrel and polymers which are non-elastic at $37^{\circ} \mathrm{C}$ showed fragmentation whereas prostheses prepared from pure PEU or Hytrel or blends of either PEU or Hytrel and polymers which are elastic at $37^{\circ} \mathrm{C}$ remained relatively unaffected after $6 \mathrm{wk}$ of implantation. Extraction experiments showed that the second polymers had formed domains in the Hytrel blends. Also differential scanning calorimetry and dynamic torsion measurements showed that the polymers were inhomogeneously dislribuled in the blends. Differential scanning calorimetry measurements on the PEU/ PLLA prostheses showed that PEU and PLLA were also inhomogeneously distributed. The crystallinity of PLLA in these blends was even higher than in the Hytrel/PLLA blends. Therefore we expect that PLLA in the PEU/ PLLA blends will not degrade more rapidly than pure PLLA and that PLLA also formed domains in the PEU matrices. Most likely the other second polymers had formed domains in the PEU blends. We conclude that fragmentation of the prostheses made of either PEU or Hytrel and polymers which are non-elastic at $37^{\circ} \mathrm{C}$ is mainly caused by alternating stresses induced by the pulsations and that (bio)degradation plays a minor role.

The rigid polymers which form domains in the PEU and the Hytrel matrices can be regarded as rigid filler particles for the elastomer. In a large variety of rubber products rigid particles, usually carbon blacks, are frequently applied. One of the objectives is to improve the mechanical properties of the rubber. Important parameters are the adhesion of the filler particles and the rubber and the size of the filler particles. In the case of carbon blacks, reinforcement is obtained because of the specific interaction and the large contact area between the rubber matrix and the filler particles. With our prostheses a strong adherence between the PEU or Hytrel matrices and the domains formed by the second polymers is not likely and since the domain size is several micrometres in diameter the contact area is relatively small. Therefore these filler particles will have a counteracting effect on the mechanical properties of the prostheses and should be regarded as flaws. Since flaws act as stress concentrators during repeated stretching, the failure process is initiated near these domains. This process may be influenced by surrounding fluids [stress 
corrosion) whereby the rate of degradation of the (bio)degradable polymer is not influenced.

Differences in the degree of fragmentation were found for the different prostheses made of blends of either PEU or Hytrel and polymers which are non-elastic at $37^{\circ} \mathrm{C}$. For example the PEU/PLLA(MM) and the Hytrel/PLLA(LM) prostheses were fragmented more extensively than the PEU/PLLA(HM) and the Hytrel/PLLA(HM) prostheses respectively. Since low-molecular-weight PLLA degrades faster than high-molecular-weight PLLA there may be some influence of (bio)degradation on the fragmentation rate. But it is also possible that the size of the PLLA domains in the different prostheses was not equal which will also affect the fragmentation rate. The in vivo behaviour of the Hytrel-based prostheses corresponds to that of the PEU-based prostheses but the differences in the degree of fragmentation of the Hytrel-based prostheses are less pronounced than those of the corresponding PEU-based prostheses. Several reasons may account for this. The adherence of the non-elastic domains to the elastic matrix and the size of the domains are most likely not the same in both types of prostheses. These differences will strongly affect the fragmentation rate. Furthermore differential scanning calorimetry showed differences in the crystallinity of PLLA in the PEU/PLLA and the Hytrel/PLLA blends. These differences might be related to differences in the degree of compatibility of the polymers which in turn will influence the fragmentation rate.

Despite the excellent results obtained with the PEU/ PLLA prostheses in vivo, care must be exercised to apply these types of prostheses clinically. As has been shown by van der Lei et al., polymer particles of the fragmented prostheses are engulfed by multinucleated giant cells ${ }^{7,8}$. However, it is unknown how long it takes until the polymer particles are degraded completely and whether the degradation products accumulate in the body. Furthermore, evidence has been gathered that toxic compounds are generated during the degradation of polyurethanes. Especially when the hard segments of the used polyurethanes are composed of aromatic diisocyanates like methylene bis( $p$-phenylisocyanate) in for example Biomer ${ }^{\circledR}$, Mitrathane ${ }^{\circledR}$, Pellethane ${ }^{\circledR} 2363$ series and Estane ${ }^{\circledR} 5714 \mathrm{f} 1$, aromatic diamines are formed which are carcinogenic, mutagenic and very toxic ${ }^{24-30}$. Promising in this regard is the work of Bruin et al. ${ }^{31}$ who synthesized polyester-urethane elastomer networks from the nontoxic compounds L-lactic acid, glycolide, $\varepsilon$-caprolactone, lysine and mycoinositol. In principle, the choice of the polymers is not restricted to polyurethanes. Also, the application of other polymers with elastomeric properties at $37^{\circ} \mathrm{C}$ can be considered. Such elastomers should meet the following requirements. The elastomer must degrade into non-toxic compounds, preferably into naturally occurring metabolites. The physical and chemical properties of the elastomer must be such that a prosthesis with the desired pore structure and mechanical properties can be prepared. The surface characteristics of the elastomer must be such that the prosthesis allows ingrowth and overgrowth of the surrounding tissue thereby inducing regeneration of the arterial wall. The elastomer and its degradation products must not provoke undesired tissue reactions. The compliance of the implant must be maintained in time which implies that the degradation rate of the prosthetic material must be balanced with the regeneration rate of the arterial wall. This study has shown that when an elastomer is blended with a non-elastic incompatible polymer the non-elastic polymer forms domains in an elastic matrix. As a consequence, the fragmentation rate is enhanced. The fragmentation rate can be adjusted by changing the type of non-elastic polymer or changing the elastomer/nonelastic polymer ratio or both.

\section{ACKNOWLEDGEMENTS}

This study was financially supported by the Dutch Technology Foundation (STW). The authors wish to thank H.L. Bartels (Central Animal Laboratory, University of Groningen, Groningen, The Netherlands) for his microsurgical assistance.

\section{REFERENCES}

1 Berger, K.E., Sauvage, L.R., Rao, A.M. and Wood, S.J., Healing of arterial prostheses in man: its incompleteness, Ann. Surg. 1971, 175, 118-127

2 Sauvage, L.R., Berger, K.E., Wood, S.J., Yates, S.G. Smith, J.C. and Mansfield, P.B., Interspecies healing of porous arterial prostheses. Observations, 1960 to 1974 Arch. Surg. 1974, 109, 698-705

3 Walden, R., L'Italien, G.J., Megerman, J. and Abbott, W.M., Matched elastic properties and successful arterial grafting, Arch. Surg. 1980, 115, 1166-1169

4 Kinley, C.E. and Marble, A.E., Compliance: a continuing problem with vascular grafts, J. Cardiovasc. Surg. 1980, 21, 163-170

5 Abbott, W.M., Megerman, J., Hasson, J.E., L'Italien, G. and Warnock, D.F., Effect of compliance mismatch on vascular graft patency, J. Vasc. Surg. 1987, 5, 376-382

6 van der Lei, B., Darius, H., Schrör, K., Nieuwenhuis, P., Molenaar, I. and Wildevuur, Ch.R.H., Arterial wall regeneration in small-caliber vascular grafts in rats. Neointimal healing and prostacyclin production I. Thorac. Cardiovasc. Surg. 1985, 90, 378-386

7 van der Lei, B., Bartels, H.L., Nieuwenhuis, P. and Wildevuur, Ch.R.H., Microporous, compliant, biodegradable vascular grafts for the regeneration of the arterial wall in rat abdominal aorta, Surgery 1985, 98, 955-963

8 van der Lei, B., Wildevuur, Ch.R.H., Nieuwenhuis, P., Blaauw, E.H., Dijk, F., Hulstaert, C.E. and Molenaar, I. Regeneration of the arterial wall in microporous, compliant biodegradable vascular grafts after implantation into the rat abdominal aorta. Ultrastructural observations, Cell Tissue Res. 1985, 242, 569-578

9 van der Lei, B., Wildevuur, Ch.R.H. and Nieuwenhuis, P., Compliance and biodegradation of vascular grafts stimulate the regeneration of elastic laminae in neoarterial tissue. An expcrimental study in rats, Surgery 1986, 99, 45-52

10 van der Lei, B., Wildevuur, Ch.R.H., Dijk, F., Blaauw, E.H., Molenaar, I. and Nieuwenhuis, P., Sequential studies of arterial wall regeneration in microporous, compliant, biodegradable small-calibre vascular grafts in rats, $J$. Thorac. Cardiovasc. Surg. 1987, 93, 695-708

11 van der Lei, B., Nieuwenhuis, P., Molenaar, I. and Wildevuur, Ch.R.H., Long-term biological fate of neoarteries regenerated in microporous, compliant, bio- 
degradable small-calibre vascular grafts in rats, Surgery $1987,101,459-468$

12 Wildevuur, Ch.R.H., van der Lei, B. and Schakenraad, J.M., Basic aspects of the regeneration of small-calibre neoarteries in biodegradable vascular grafts in rats, Biomaterials 1987, 8, 418-422

13 Gogolewski, S. and Pennings, A.J., Biodegradable materials of polylactides. 4. Porous biomedical materials based on mixture of polylactides and polyurethanes, Macromol. Chem. Rapid Commun. 1982, 3, 839845

14 Gogolewski, S. and Pennings, A.J., Compliant, hiodegradable vascular prosthesis, in Polyurethane in Biomedical Engineering (Eds H. Planck, G. Egbers and I. Syré), Elsevier Science Publishers B.V., Amsterdam, The Netherlands, 1985, pp 279-285

15 Reed, A.M. and Gilding, D.K., Biodegradable polymers for use in surgery - poly(glycolic)/poly(lactic acid) homo and copolymers: 2. In vitro degradation, Polymer 1981, 22, 494-498

16 Gilding, D.K., Biodegradable polymers, in Biocompatibility of Clinical Implant Matcrials (Ed. D.F. Williams), Boca Raton, CRC Press, FL, USA, 1981, pp 209-232

17 Jamshidi, K., Hyon, S.-H., Nakamura, T., Ikada, Y., Shimizu, S. and Teramatsu, T., In vitro and in vivo degradation of poly-L-lactide fibers, in Biological and Biomechanical Performance of Biomaterials (Eds P. Christel, A. Meurier and A.J.C. Lee), Elsevier Science Publishers B.V., Amsterdam, The Netherlands, 1986, pp 227-232

18 Leenslag, J.W., Kroes, M.T., Pennings, A.J. and van der Lei, B., A compllant, biodegradable vascular graft: basic aspects of its construction and biological performance, New Polymeric Mater. 1988, 1, 111-126

19 Schindler, A., Hibionada, Y.M. and Pitt, C.G., Aliphatic polyesters. 3. Molecular weight and molecular weight distribution in alcohol initiated polymerization of $\varepsilon$-caprolactone, J. Polym. Sci., Polym. Chem. Edn 1982, 20, 319-326

20 Schindler, A. and Harper, D., Polylactide. 2. Viscositymolecular weight relationships and unperturbed chain dimensions, J. Polym. Sci., Polym. Chem. Edn 1979, 17, 2593-2599

21 Crescenzi, V., Manzini, G., Calzodari, G. and Borri, G., Thermodynamics of fusion of poly- $\beta$-propioloacetone and poly- $\varepsilon$-caprolacton. Comparative analysis of the melting of aliphatic polylactone and polyester chains, Eur. Polym. J. 1972, 8, 449-463

22 Fischer, E.W., Sterzel, H.J. and Wegner, G., Investigations of the structure of solution grown crystals of lactide copolymers by means of chemical reactions, Kolloid $Z$. $Z$. Polym. 1973, 251, 980-990

23 Product information published in commercial brochures on Estante 5714 f1 (Goodrich, Leidschendam, The Netherlands) and Hytrel ${ }^{\circledast} 4056$ (Du Pont de Nemour, Mechelen, Belgium]

24 Batich, C., Williams, J. and King, R., Toxic hydrolysis product from a biodegradable implant, $J$. Biomed. Mater. Res. 1989, 23, 311-319

25 Paynter, R.W., Askill, I.N., Glick, S.H. and Guidon, R., The hydrolytic stability of Mitrathane (a polyurethane urea) - an X-ray photoelectron spectroscopic study, J. Biomed. Mater. Res. 1988, 22, 687-698

26 Marchant, R.E., Zhao, Q., Anderson, J.M. and Hiltner, A., Degradation of poly(ether urethane urea) elastomer: infra-red and XPS studies, Polymer 1987, 28, 2032-2039

27 Phua, S.K., Castillo, E., Anderson, J.M. and Hiltner, A., Biodegradation of polyurethane in vitro, $J$. Biomed. Mater. Res. 1987, 21, 231-246

28 Smith, R., Williams, D.K. and Oliver, C.. The biodegradation of poly(ether urethanes), $J$. Biomed. Mater. Res. 1987, 21, 1149-1166

29 Lelah, D.M. and Cooper, S.L., in Polyurethanes in Medicine, CRC Press, Boca Raton, FL, USA, 1986

30 Lipatova, T.E., Some chemical aspects of the behaviour of synthetic polymers in a living organism, J. Polym. Sci., Polym. Symp. 1979, 66, 239-257

31 Bruin, P., Veenstra, G.J., Nijenhuis, A.J. and Pennings, A.J., Design and synthesis of biodegradable poly(esterurethane) elastomer networks composed of non-toxic building blocks, Makromol. Chem., Rapid Commun. 1988, 9, 589-594 